\title{
Evaluation of the efficacy of a family sized solar cabinet dryer in food preservation
}

\author{
J.I. Eze \\ National Centre for Energy Research and Development, University of Nigeria, Nsukka \\ E-mail: ikejon85@yahoo.com
}

\begin{abstract}
A family size solar cabinet dryer was designed, constructed and its performance evaluated using cassava roots. Wooden, metallic and glass materials were used for the construction of the familysized solar dryer and freshly harvested cassava roots used to evaluate the drying efficiency of the system in the preservation of cassava and cassava-based products. The proximate composition of the cassava roots including its cyanide content, mould count, $\mathrm{pH}$ and water activity before subjecting it to the two modes of drying used in this research were noted. The cassava roots were peeled, cut into chips of $4 \mathrm{~cm}$ long, $1 \mathrm{~cm}$ wide and $1 \mathrm{~cm}$ thick, washed and divided into 5 parts, 3 parts were soaked separately for 1, 2 and 3 days respectively, while the other 2 parts were sundried and solar-dried for 3 days. Samples were collected every day to determine the $\mathrm{pH}$, water activity and moisture content. For the soaked samples, after each day of soaking, they were divided into 2 parts; 1 part was sun dried and the other was solar dried. The $\mathrm{pH}$, water activity and moisture content, mould count and cyanide contents of the various samples were determined. Results obtained show that soaking and solar-drying reduced the cyanide and mould counts in cassava more than soaking and open-air sun-drying. Data obtained from the sensory evaluation showed that the colour and odour of all the solar- dried samples were preferred to those of the sun dried samples.
\end{abstract}

Keywords: Solar dryer, cyanide

\section{INTRODUCTION}

Drying of produce is a vital operation in the chain of food handling. The basic essence of drying is to reduce the moisture content of the product to a level that prevents deterioration within a certain period of time, normally regarded as the "safe storage period" (Ekechukwu, 1987). Technically, drying in its ordinary application, is a heat and mass transfer process, involving vapourisation of water in the liquid state, mixing the vapour with the drying air and removing the vapour by naturally or mechanically carrying away the mixture, often vapour and moisture (Sharma et al, 1987). Sufficient heat for vapourisation of product moisture must be supplied by reducing the sensible heat of the drying air or by applying heat directly to the product by conduction, radiation, dielectric heating, freeze-drying etc. Utilizing the sensible heat content of the air is by far the most common means of drying (Ezekwe, 1995). Drying rates could be controlled by monitoring either the heat supply or the relative humidity of the surrounding air or by both. Drying process is therefore, controlled by the properties of the drying air, often known as external parameters, and the properties of the material to be dried i.e. internal parameters. The objective of a dryer is to supply the product with more heat than is available under ambient conditions, thus increasing sufficiently the vapour pressure of the moisture held within the crop and decreasing sufficiently the relative humidity of the drying air, thus increasing the moisture -carrying capacity and ensuring sufficiently low equilibrium moisture content (Ekechukwu, 1987).

Different methods of drying food for purpose of preservation are as follows:

a) Traditional or open air sun drying

b) Conventional drying technique

c) Solar drying technique.

Solar drying technique: Solar drying as a means of food preservation seems to be the most promising and modest approach for preservation of various agricultural products. In solar drying, solar energy is used as either the sole source of the required heat or as a supplemental source. The air flow can be generated by either natural or forced convection. Solar drying offers the following advantages over sun drying: faster drying rate, greater retention of vitamins, especially vitamins $A$ and $C$, minimizing damage from rain, protection against infection etc, 
and also some advantages over the conventional drying with respect to cost and adaptability to small scale farmers. Some of the crops commonly grown in developing countries may be better suited to solar drying than to fossil fuel drying systems because case -hardening and other damages are likely to be less at low temperature characteristics of solar dryers (Ezekwe, 1995).

Solar dryers are a promising means for tropical countries to meet their requirements as the available amount of solar energy in most cases is sufficient to cover the heat requirements for small dryers. Solar dryers are generally classified into two basic categories; the passive (natural-convection) dryers and active (forced-convection) dryers.

The natural-convection aeration principle is based on the temperature difference and consequently, the difference in the density of the air inside and outside the drying chamber. Natural-convection dryers do not require any mechanical or electrical power to run a fan, the construction is simple, easy to maintain and inexpensive. On the other hand, the working mechanism is strongly dependent on the temperature difference and the pressure drop which occurs when air is forced through the crop. Forced-convection solar dryers generally show several advantages such as high reliability. On the other hand, they require a cover to force air through or over the product. In contrast to natural-convection dryers is dependent on electrical power. Hence, the electricity costs have to be compensated with reduction in drying time, higher drying capacity, reduction of mass losses and better quality of the product.

Aims and objectives: This research is aimed strictly at the following objectives:

1) Design and construction of a family size solar cabinet dryer for food preservation.

2) Evaluation of the drying efficiency of the solar cabinet dryer in food preservation.

3) Comparative assessment of the sensory qualities (colour and odour) of solar-dried and open-air sun dried food product.

\section{MATERIALS AND METHODS}

Design and construction of the cabinet solar dryer: To make a solar dryer techno-economically feasible, one must first take into account the thermodynamics of the system. These refer to all heat; mass and humidity calculations and then fix the major parameters like quantity of air required, moisture removed from the product; rise and fall of air temperature, and collector dimensions. The mechanical design considerations concentrate on fixing the mechanical details of the drying chamber, the perforated sheet and the wire-mesh, the pressure drop through the dryer etc. The mechanical details of the drying chamber require studies regarding cabinet size, tray area, number of trays required, depth of materials in the trays, clearance between two trays, plenum chamber height and top clearance area. Other design parameters taken into account are:

(a) The layout of the drying chamber to hold the material to be dried.

(b) A system for loading and unloading the material.

(c) A system (natural or forced convection) to pass the hot air through the material mass.

(d) A controlled monitoring system to dry the material to the desired extent.

(e) The capacity of the dryer to be constructed (in kg/day).

(f) Geographical location and climatic conditions.

(g) Availability of solar insulation.

(h) Variations in ambient temperature, relative humidity, wind velocity at the location.

(i) Considerations including initial and desired moisture content of the material (Sharma, et al 1987)

Design of the cabinet solar dryer: In the construction of the cabinet solar dryer, the length of the cabinet was chosen to be between $2.5-3.0 \mathrm{~cm}$ times the width to minimize shading effect from the side panels. The dryer is essentially a single chamber cabinet iron frame covered with Perspex (colorless glass which provides substantial screening effect against ultraviolet light, thus reducing photodegradation of the produce being dried) (Sharma, et al 1987). Its bottom and door are insulated with plywood for reduction in heat losses and together with the roof blackened for effective absorption and retention of solar radiation. Holes drilled in the bottom is for inlet of air which is solar heated and passed through the wire-mesh tray on which the material to be dried is spread.

Construction of the cabinet solar dryer: The iron sheets were measured using the measuring tape. The Perspex (glass) of about $3 \mathrm{~mm}$ thick was measured and cut to the desired size and length, then used to cover the frame. It was held to the frame with nuts and bolts. The door and bottom of the dryer 
were insulated with plywood. Door, bottom and chimney were painted black. The wire mesh tray of length-0.9m, width- $0.36 \mathrm{~m}$ and depth- $0.375 \mathrm{~m}$ was constructed and put into the drying chamber. Holes (6 holes) of about $1.4 \mathrm{~cm}$ diameter and well spaced were drilled in the insulated bottom of the dryer (Plate 1).

Operation of a cabinet solar dryer: The two principle phases of the process in solar drying are:

- $\quad$ The solar heating of the working gas (air) and,

- The drying itself (where the heated air extracts moisture from the particles).

During drying, air is sucked in through the holes in the bottom of the dryer. The sucked in air is heated by the absorbed solar radiation .As warm air passes through and over the produce to be dried, it removes moisture from the surface of the produce and becomes moist. The warm moist air goes out through the chimney by natural convection, creating a partial vacuum and drawing fresh air up through the holes provided in the base of the dryer (Garg, 1987).

Procurement of raw materials: Mature, harvested cassava (Manihot esculenta) was purchased from the University of Nigeria, Nsukka farm. The cassava was washed thoroughly with clean water then peeled, and sliced into strips of length $4 \mathrm{~cm}$, width- $1 \mathrm{~cm}$ and thickness- $1 \mathrm{~cm}$ and then washed again.

The sliced cassava strips were divided into 5 parts. One part was subjected to solar drying for 3 days. The second part was sun-dried for 3 days. The remaining 3 parts were then soaked separately for one, two and three days respectively after which each was divided into two parts. One part was sun dried and the other part solar -dried for the same number of days with which it was soaked (Fig. 1). The cassava strips were soaked in order to reduce its cyanide content.

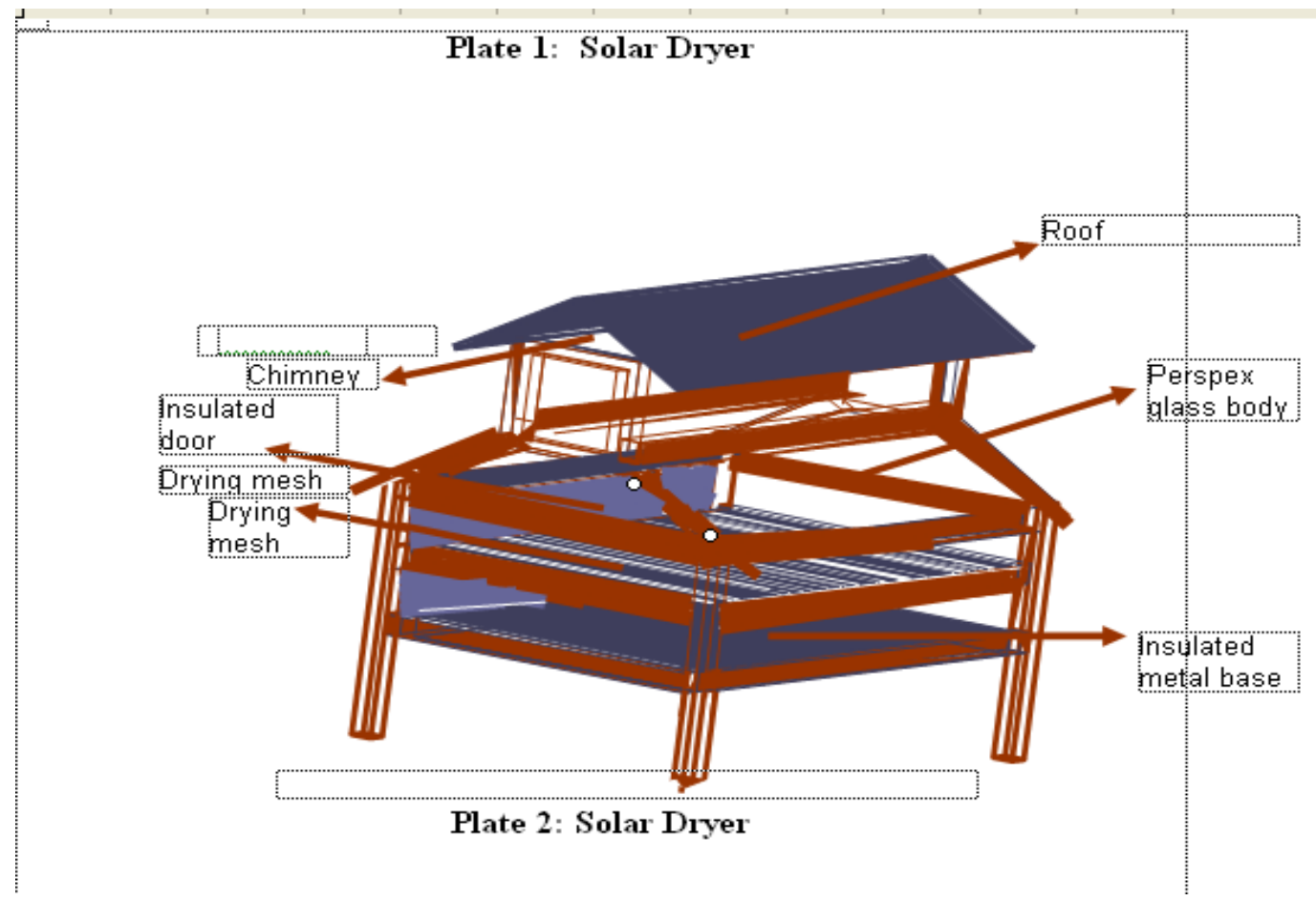


Am. J. Sci. Ind. Res., 2010, 1(3): 610-617

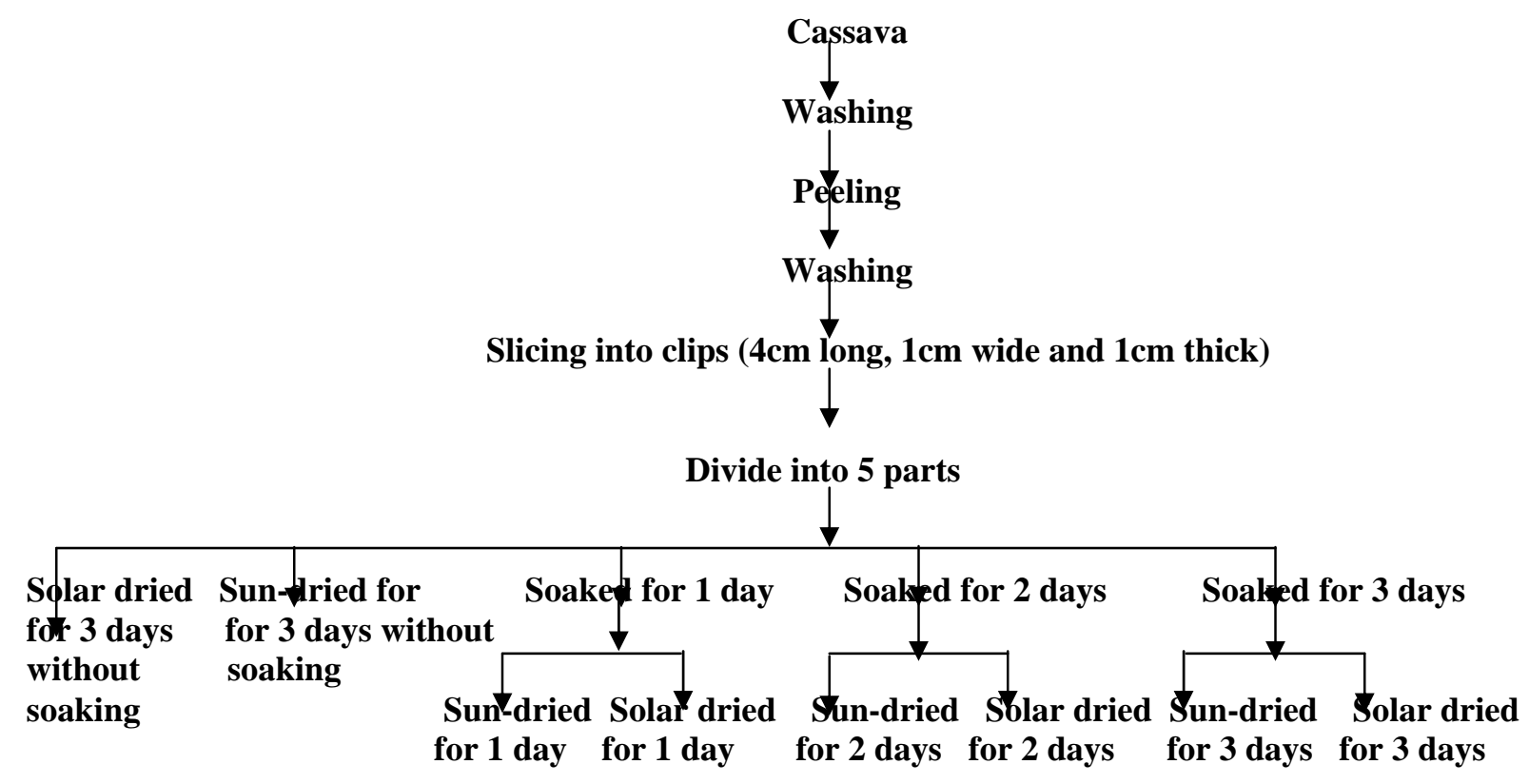

Fig 1: Flow diagram illustrating sample preparation

The following analyses were carried out both before and after drying in order to determine the efficiency of drying using the family sized solar cabinet drier as compared to sun drying.

a. Proximate composition (Crude protein, crude fat, crude fiber, ash, moisture content and carbohydrate content) was carried out using AOAC methods.

b. Mould count was carried out using the method stipulated in Okore et. al., 2004.

c. Cyanide content was obtained using the method described by Onwuka, (2005).

d. $\mathrm{pH}$ was determined using the Orion expandable ion analyzer.

e. Water activity of the samples was determined using the $a_{w}$-value analyzer.

f. Temperature was determined by the use of a thermometer.

g. Solar insulation was determined every 1 hour as the amount of sunshine per hour in $\mathrm{W} / \mathrm{m}^{2}$ by using the instrument Sensol monokristallin . h. Relative humidity of the atmosphere was determined by monitoring the dry-bulb and wet-bulb temperatures and a standard hygrometric chart.

i. Subjective colour and odour description were evaluated for 3 days using a semitrained 10 man panel with 7-point hedonic scale.

\section{RESULTS AND DISCUSSION}

After construction of the solar drier, it was tested empty and the maximum cabinet temperature was $55^{\circ} \mathrm{C}$ at an ambient temperature of $37^{\circ} \mathrm{C}$ and relative humidity of $49 \%$. The result of the proximate composition of the raw cassava (Table 1) indicates a moisture of $75 \%$, crude protein content of $2.5 \%$, crude fat $0.3 \%$, crude fiber $1.1 \%$, ash $1.0 \%$ and carbohydrate content of $20.1 \%$. This result agrees to an extent with the results obtained by Ihekoronye and Ngoddy (1985). 
Am. J. Sci. Ind. Res., 2010, 1(3): 610-617

Table 2: Results on analysis before drying

\begin{tabular}{|l|l|}
\hline Test/ analysis & Composition (\%) \\
\hline Moisture & $75 \%$ \\
Protein & $2.5 \%$ \\
Fat & $0.3 \%$ \\
Fiber & $1.1 \%$ \\
Ash & $1.0 \%$ \\
Carbohydrate & $20.1 \%$ \\
pH & 4.30 \\
Water activity & 0.90 \\
Cyanide content (ppm) & $223 \mathrm{ppm}$ \\
Mould content & $3.14 \times 10^{5}$ \\
\hline
\end{tabular}

Table 3: Effect of drying on $\mathrm{pH}$

\begin{tabular}{|l|l|l|l|}
\hline \multirow{2}{*}{ Samples } & \multicolumn{3}{|c|}{ Number of days } \\
\cline { 2 - 4 } & 1 day & 2 days & 3 days \\
\hline Soaked & 4.019 & 4.010 & 3.709 \\
\hline Solar dried & 4.820 & 3.971 & 3.798 \\
\hline Sundried & 4.607 & 4.207 & 3.796 \\
\hline
\end{tabular}

(Initial pH before soaking or Drying-:4.030)

The mean environmental data generated during drying is shown in Table 5. Increase in the dryer temperature above ambient temperature is as a result of the concentration of heat in the dryer due to the trapped radiant energy by the dryer. This is to say that the solar cabinet is an efficient device for solar drying of foods as is evident in its ability to absorb radiant heat thereby increasing its internal temperature above that of ambient temperature.

It is observed in Table 3 above that the initial $\mathrm{pH}$ of cassava which was 4.030 was further reduced to $4.019,4.010$ and 3.971 after the cassava was soaked for 1,2 and 3 days respectively. This is due to the formation of acids since fermentation is taking place and acids being one of the fermentation products is formed, thereby leading to reduction in $\mathrm{pH}$ and increase in acidity of the cassava samples. It was observed that when these samples were dried (for 1 , 2 and 3 days) there was increase in $\mathrm{pH}$ with the solar dried samples increasing more than the sun dried samples. The increase in $\mathrm{pH}$ during drying is as a result of a reduction in the cyanide content. As drying was going on, there was a reduction in the cyanide content thereby loosing some of the hydrogen ion concentration which is from the cyanide, thereby resulting in the acidity of the samples and increasing the $\mathrm{pH}$. Since the solar dried samples have higher $\mathrm{pH}$, it is an indication of the efficiency of the solar cabinet dryer which to an extent can be used for drying during cassava processing.
Prior to drying, the cassava chips were divided into 5 parts. The first part was solar dried for 3 days and the second part sun-dried for 3 days. During drying, samples were collected on a daily basis to determine moisture loss. There was appreciable moisture loss from the solar dried samples than the sun-dried ones as shown in figure 2-4; this is a very good indication of how efficient the solar dryer is for the reduction of moisture content of food produce. Absorption of radiant heat by the solar dryer which heats up the incoming air thereby increasing the temperature of the air and since this air is inside the dryer, it removes moisture from the cassava until it can no longer remove moisture (Fig 2-4). The moisture containing air then leaves the dryer giving room for more air to come in which is not the case during sundrying which is a natural radiation drying process.

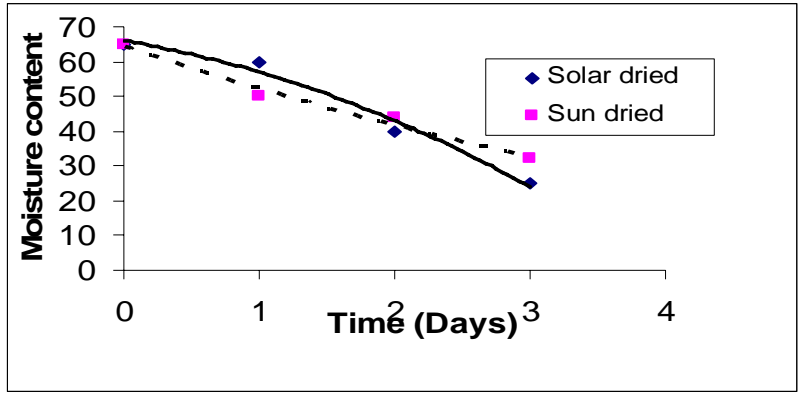

Fig.2. Effect of drying on the moisture content of both solar dried and Sun dried unsoaked samples 


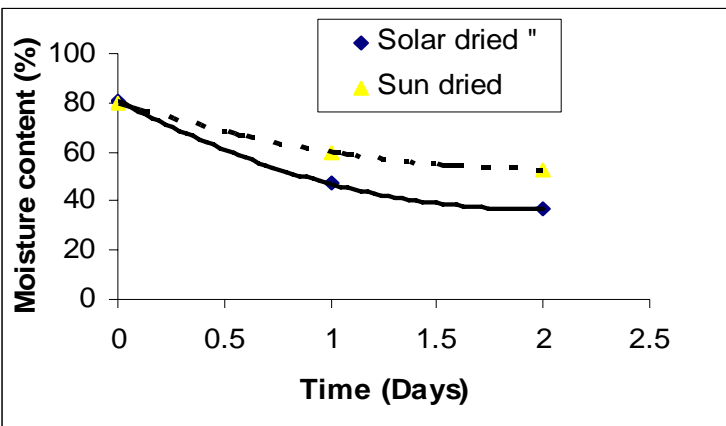

Fig.3. Effect of drying on the moisture content of soaked sample that was both solar dried and Sun dried for 2 days

Efficient removal of moisture by solar drying resulted in a lower water activity of solar dried samples than the sun dried samples as shown on figure 5-8

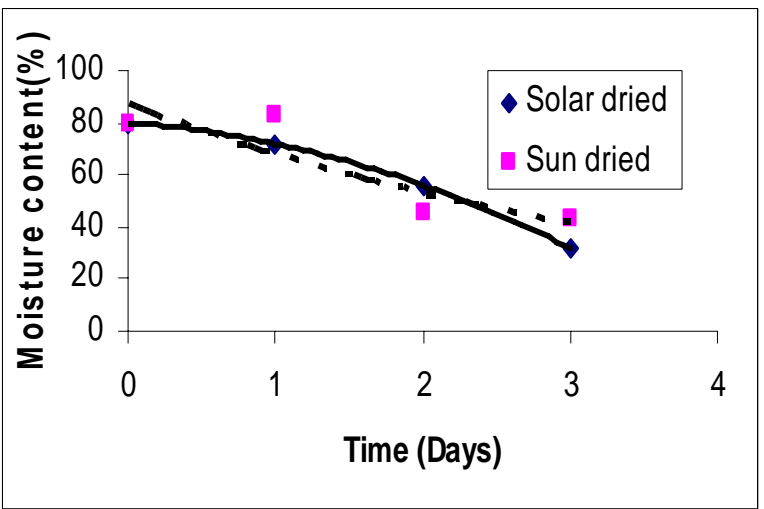

Fig.4. Effect of drying on the moisture content of the sample soaked for 3 days and both solar dried and Sun dried for 3 days

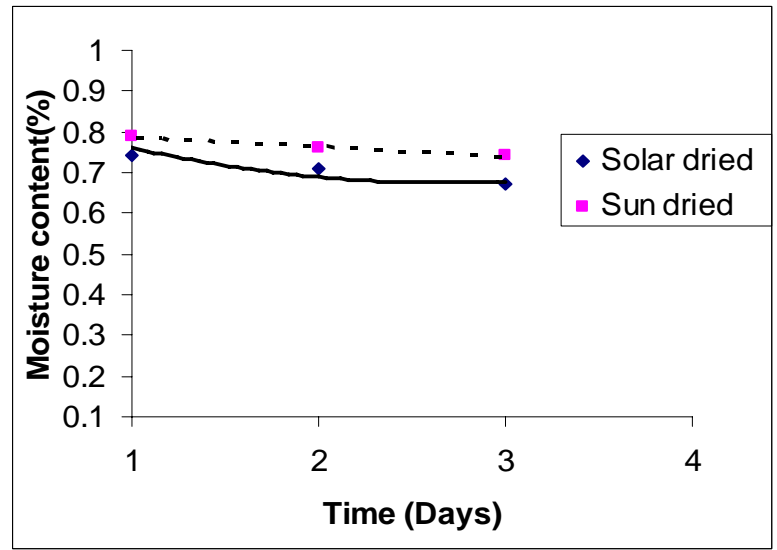

Fig.5: Effect of drying on the water activity of the unsoaked samples both solar dried and sun dried for 3 days.

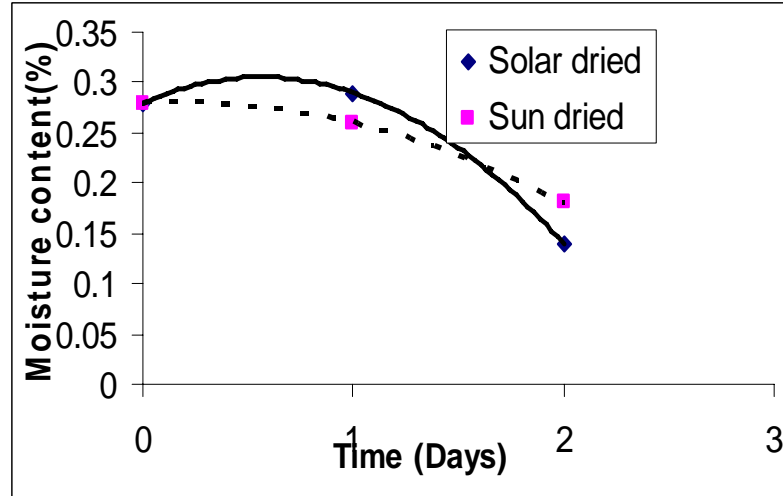

Fig.6. Effect of drying on the water activity of the soaked sample for 2 days and both solar dried and Sun dried for 2 days

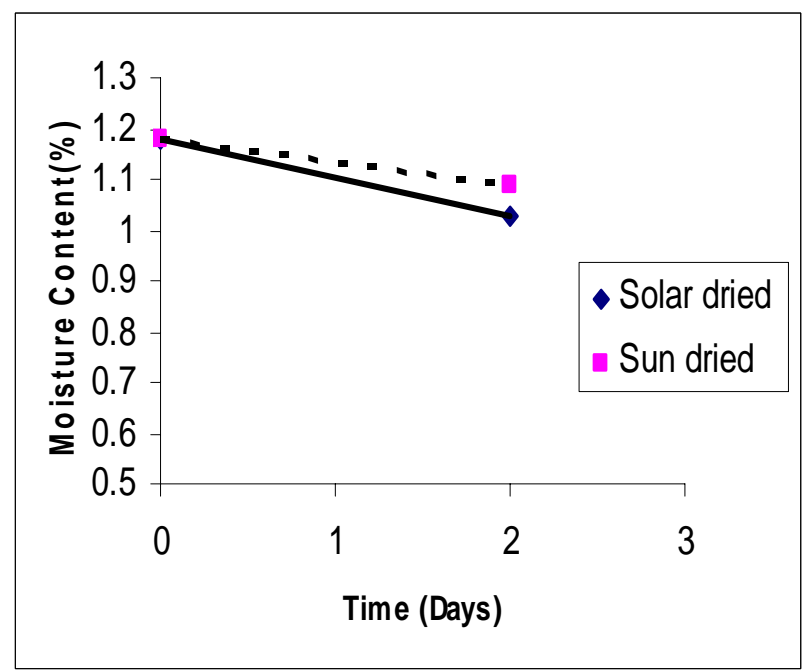

Fig.7. Effect of drying on the water activity of the soaked sample for 1 day and both solar dried and Sun dried for 1 day

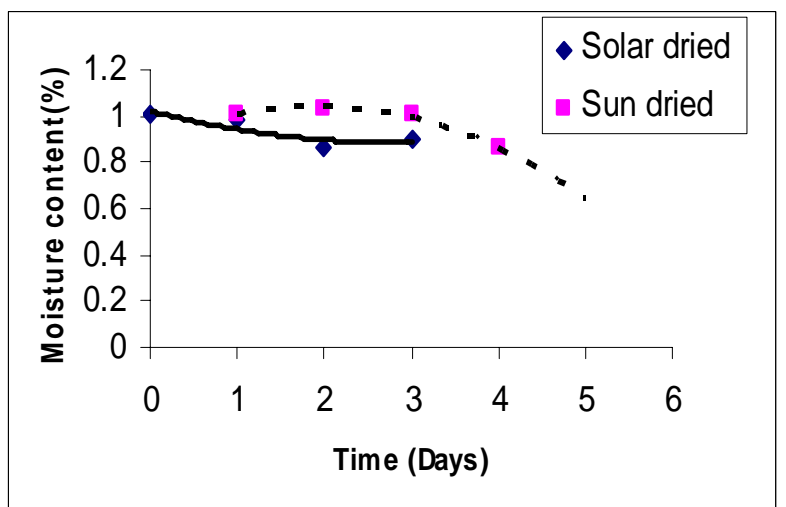

Fig.8. Effect of drying on the water activity of the sample for 3 days and both solar dried and Sun dried for 3 days 
Am. J. Sci. Ind. Res., 2010, 1(3): 610-617

Table 5: Effect of Drying on the cyanide and Mould content of the samples both soaked and dried for three days each.

\begin{tabular}{|l|l|l|l|l|}
\hline Parameters & \multicolumn{2}{|l|}{ Soaked samples } & Unsoaked samples \\
\cline { 2 - 5 } & Cyanide content & Mould & Cyanide content & Mould \\
\hline $\begin{array}{l}\text { Fresh I undried } \\
\text { samples }\end{array}$ & 67.1 & 1.0 & 223 & 3.14 \\
\hline $\begin{array}{l}\text { Solar dried } \\
\text { samples }\end{array}$ & 37.1 & 1.02 & 206 & 2.15 \\
\hline $\begin{array}{l}\text { Sun dried } \\
\text { samples }\end{array}$ & 41.1 & 2.0 & 209 & 2.2 \\
\hline
\end{tabular}

After soaking for 3 days, there was appreciable reduction in the cyanide content from 223-67ppm (Table 5) this is as a result of removal of cyanide during soaking by bacterial fermentation. It is known that drying reduces cyanide content and this was more pronounced in the solar dried samples than in the sun dried samples because of the higher temperature in the solar dryer. Initial cyanide and mould content of the cassava strips was 223 and 3.14 respectively)

Solar dried samples were low in mould count than the sun dried samples as shown in Table 5 above. This is due to the fact that the solar dried samples had less moisture content and low water activity than the sun dried samples thereby making moisture not readily available for mould growth. Also, the temperature of the cabinet dryer retards mould growth and the inherent mould content of samples were prevented from growing during drying unlike in sun-drying where the temperature is not as high as that of the solar dryer and therefore very conducive for microbial growth especially mesophillic microorganisms of which moulds are examples.

The sensory assessment showed that the solar dried samples were preferred in colour and odor than the sun-dried samples (Tables 6 and 7). This is as a result of screening the samples from direct solar radiation by the solar dryer thereby preserving the color and efficient removal of the odorous compounds which are volatile and are removed as vapor since the heat of the dryer is high enough to remove them.
Table 6: Sensory assessment of soaked samples

\begin{tabular}{|l|l|l|}
\hline Samples & Colour & Odour \\
\hline $\begin{array}{l}\text { soaked and solar dried } \\
\text { for 3 days } \\
\text { soaked and sun dried } \\
\text { for 3 days }\end{array}$ & 7.7 & 6.6 \\
\hline
\end{tabular}

Table 7: Sensory assessment of unsoaked samples

\begin{tabular}{|l|l|l|}
\hline Samples & Colour & Odour \\
\hline Solar dried for 3 days & 5.8 & 5.6 \\
Sun dried for 3 days & 5.6 & 5.4 \\
& & \\
\hline
\end{tabular}

\section{CONCLUSION}

It has been shown that using solar dryer in cassava processing can reduce the cyanide and pathogens to a harmless level. The water activity level attained during this study was at a critical level to the survivor of those micro organisms responsible for food spoilage. Also, the reduction in the cyanide content shows that drying at a higher temperature has a significant impact on the cyanide detoxification in cassava -based products. Results obtained on the sensory evaluation of the various cassava samples show that the colour and odour of the solar-dried products maintained better organoleptic qualities than other samples dried in the open air Nevertheless, when solar drying is used as a preservation technique, it should be done when the temperature of the environment is very high as this ensures maximum drying efficiency.

The author appreciates the assistance rendered to him by the staff of the Department of Food Science and Technology, University of Nigeria, Nsukka for the use of its facilities 
Am. J. Sci. Ind. Res., 2010, 1(3): 610-617

\section{REFERENCES}

A.O.A.C. (1990). Official methods of Analysis, $15^{\text {th }} \mathrm{Ed}$. Association of Official Analytical Chemists Inc. Washington D.C.

Ekechukwu, O. V. (1987). Experimental Studies of Integraltype Natural-Circulation Solar-energy. Tropical Crop Dryers. Ph. D Thesis, Cranfield Institute of Technology, United Kingdom. pp.23-52.

Ezekwe, C. I. (1995). Introduction to Solar Drying. National Center for Energy Research and Development Journal .pp 2-8

Garg, H. P. (1987). Solar Food Drying. In: Advances in Solar Energy Technology. vol.3, Heating Agricultural and Photovoltaic Application of Solar Energy, pp. 116169.

Okore V.C., Ibezim E.C. Adikwu, M.U. Attama, A.A., Esimone, C.O, Uzuegbu, B.D., Ofokansi, E.C. (2004). Laboratory Techniques in Pharmaceutics and Pharmaceutical Microbiology. $2^{\text {nd }} E d$. El'Demak Ltd Publishers, New-Layout, Enugu, pp 24-26.

Onwuka,G.I.(2005). Food Toxins. In: Food Analysis and Instrumentation Theory and Practice. Napthali Prints, Lagos. pp.142-143.

Sharma, S., Ray, R. A. and Sharma, V. K. (1987). Comparative Study of Solar Dryer for Crop Drying In: Invention Intelligence Centre for Energy Studies, Indian Institute of Technology, New Delhi, India, pp. 105-113. 